\title{
PERANCANGAN WEBSITE ENSIKLOPEDIA DIGITAL KARAENG PATTINGALLOANG
}

\author{
Handi Nurdiawan, Dian Cahyadi, Aswar \\ Desain Komunikasi Visual, Fakultas Seni dan Desain UNM \\ handinurdiawan@gmail.com \\ dian.cahyadi@unm.ac.id \\ aswar_saini@yahoo.co.id
}

\begin{abstract}
Abstrak
Karaeng Pattingalloang merupakan sosok seorang raja yang dikenal memiliki jiwa intelektual tinggi di kalangan bangsawan eropa pada pertengahan abad ke-XVII dikarenakan kecintaannya terhadap ilmu pengetahuan khususnya ilmu-ilmu barat yang dimana pada masa itu sangat jarang sekali ditemukan sosok raja seperti beliau di belahan bumi nusantara. Perkembangan teknologi pada masa kini membuat arus pertukaran informasi begitu cepat dan cenderung dinamis mudah berubah. Media pemberi informasi yang tadinya berbentuk buku cetak konvensional kini beralih ke teknologi digital. Perubahan-perubahan inilah yang melatarbelakangi perancangan website ensiklopedia digital ini. Pada perancangan website ensiklopedia digital Karaeng Pattingalloang tujuan utamanya adalah untuk memberikan alternatif baru media pemberi informasi khususnya yang membahas tentang sejarah kepada masyarakat. Fokus utama penelitian adalah dimulai dengan mengelompokkan data yang diperoleh dari hasil observasi lapangan, wawancara, studi pustaka dan sumber-sumber lainnya, kemudian dilanjutkan dengan pembuatan ilustrasi, logo website lalu kemudian merancang website sebagai media utama.
\end{abstract}

Kata Kunci: ensiklopedia digital, gowa, tallo, karaeng pattingalloang, website

\begin{abstract}
Karaeng Pattingalloang is a king who known have high intelectual among european nobles in the mid-XVII century due to his love of science especially the western science which at that time was very rare to find a king like him in the hemisphere of the archipelago.Technological in the present make the flow of information exchange so fast and tend to be dynamic, easy to change. Media providing information that used to be in the form of conventional print books are now turning to digital technology. These changes are behind the design of this digital encyclopedia website. On the design of the digital encyclopedia website Karaeng Pattingalloang the main goal is to provide a new alternative to the media providing information, especially those that discuss history to the public. The main focus of the re search is to begin by grouping the data obtained from the results of field observations, interviews, literature studies and othersources, then proceed with making illustrations, the website logo the designing the website as the main media.
\end{abstract}

Keyword: digital encyclopedia, gowa, tallo, karaeng pattingalloang, website 


\section{PENDAHULUAN}

Semua bangsa di dunia pasti memiliki cerita tentang sejarahnya masing-masing yang dapat diambil sebagai contoh pembelajaran untuk generasi yang ada saat ini maupun yang akan datang. Tidak terkecuali dengan suku Bugis-Makassar yang ada di Indonesia tepatnya di Sulawesi selatan. Dahulu kala pada masa penjajahan VOC Belanda di tanah Sulawesi, suku Bugis-Makassar terkenal anti penjajahan pada waktu itu lewat kerajaan Gowa-Tallo orang-orang bugis-makassar melakukan perlawanan menentang penjajahan.

Karaeng Pattingalloang lahir pada tahun 1600 bernama lengkap I Mangadacinna Daeng Sitaba Sultan Mahmud, Putra Raja Tallo I Malingkaang Daeng Nyonri Karaeng Matoaya. Ia pernah menjabat sebagai pelaksana Raja Tallo, karena I Mappaijo Daeng Manyuru yang diangkat sebagai Raja Tallo baru berusia 1 tahun.

Banyak cara untuk menumbuhkan kembali minat masyarakat dalam mencari informasi tentang sejarah, salah satunya ialah menambah alternatif media informasi yaitu berupa website ensiklopedia digital, selain dapat diakses dengan mudah dimanapun dan kapanpun, penggunaan media website juga tidak memerlukan banyak biaya dalam mengaksesnya sehingga sangat membantu masyarakat yang ingin mencari tahu tentang informasi sejarah khususnya sejarah Karaeng Pattingalloang. Maka dari itu perlu sebuah perancangan media ensiklopedia digital berupa website sebagai alternatif media informasi yang dapat membantu menumbuhkan kembali minat masyarakat dalam mempelajari sejarah.

Berdasarkan latar belakang diatas identifikasi masalah adalah sebagai berikut:

1. Masih kurangnya pengetahuan masyarakat mengenai sejarah Kerajaan Gowa-Tallo khususnya sejarah Karaeng Pattingalloang.

2. Kurangnya aternatif media informasi yang dikemas secara menarik mengenai sejarah tentang Karaeng Pattingalloang sehingga mengakibatkan menurunnya minat masyarakat dalam mencari tahu.

Berdasarkan identifikasi masalah diatas, penulis dapat menyimpulkan rumusan masalah sebagai berikut:
1. Bagaimana merancang sebuah media website ensiklopedia digital yang dapat menumbuhkan kembali minat masyarakat untuk mempelajari sejarah yang ada di Sulawesi selatan?

2. Bagaimana merancang tampilan visual sebuah website tentang sejarah Karaeng Pattingalloang kepada audiens dalam sebuah media berupa website ensiklopedia digital?

Untuk menghindari ruang lingkup permasalahan yang terlalu luas, maka ditetapkan batasan masalah yaitu:

1. Perancangan ini terbatas pada perancangan ensiklopedia digital berbasis website sebagai media untuk menyampaikan sejarah tentang Karaeng Pattingalloang.

2. Studi penelitian dibatasi pada lingkup sejarah Karaeng Pattingalloang.

3. Website ini ditargetkan untuk semua kalangan terkhusus untuk masyarakat Gowa, Makassar dan Sulawesi selatan pada umumnya.

Berdasarkan permasalahan yang diteliti, maka maksud dari perancangan ini adalah untuk membuat website ensiklopedia digital mengenai sejarah Karaeng Pattingalloang. Adapun tujuan dari perancangan ini adalah sebagai berikut:

1. Untuk mengenalkan sejarah dan nilai-nilai katauladanan dari seorang Karaeng Pattingalloang.

2. Menambah alternatif media pemberi informasi tentang sejarah yang relevan dan sesuai perkembangan zaman.

3. Meningkatkan minat masyarakat dalam mencari tahu informasi khususnya yang berkaitan dengan sejarah yang ada di Sulawesi Selatan. Website atau situs web adalah keseluruhan halaman-halaman web yang terdapat dalam sebuah domain yang mengandung informasi. Sebuah website biasanya dibangun atas banyak halaman web yang saling berhubungan. Hubungan antara satu halaman web dengan halaman web yang lainnya disebut dengan hyperlink, sedangkan teks yang dijadikan media penghubung disebut hypertext.

Menurut Arief (2011a:8) Pengertian website adalah: "kumpulan dari halaman web yang sudah dipublikasikan di jaringan internet 
dan memiliki domain/URL (Uniform Resource Locator) yang dapat diakses semua pengguna internet dengan cara mengetikan alamatnya". Hal ini dimungkinkan dengan adanya teknologi World Wide Web (WWW) fasilitas hypertext guna menampilkan data berupa teks, gambar, animasi, suara dan multimedia lainnya data tersebut dapat saling terhubung pada web server untuk dapat di akses melalui jaringan internet. Agar data pada web dapat di baca kita harus menggunakan web server terlebih dahulu seperti Mozila Firefox, Internet Explorer, Opera Mini atau yang lainnya.

Menurut Sibero (2011b:11) "Website adalah suatu sistem yang berkaitan dengan dokumen digunakan sebagai media untuk menampilkan teks, gambar, multimedia dan lainnya pada jaringan internet".

Menurut KBBI (2005), ensiklopedia berarti buku atau serangkaian buku yang menghimpun keterangan atau uraian tentang berbagai hal dalam bidang seni dan ilmu pengetahuan, yang disusun menurut abjad atau menurut lingkungan ilmu. Dalam KBBI pula, istilah elektronik berarti alat yang dibuat berdasarkan prinsip elektronika; hal atau benda yang menggunakan alat-alat yang dibentuk atau bekerja atas dasar elektronika. Dari pengertian di atas, ensiklopedia elektronik adalah ensiklopedia yang dimuat dalam media elektronik.

Digital adalah kata, gambar, dan grafis yang mendeskrepsikan dalam bentuk numeris melalui piranti komputer (Tom E Rolnicki, pengantar dasar jurnalisme 2008, prenada media grup rawangmangu jakarta dialihbahasakan oleh Tri Wibowo halaman 410).

Digital berasal dari kata Digitus, dalam bahasa Yunani berarti jari jemari. Apabila kita hitung jari jemari orang dewasa, maka berjumlah sepuluh (10). Nilai sepuluh tersebut terdiri dari 2 radix, yaitu 1 dan 0 , oleh karena itu Digital merupakan penggambaran dari suatu keadaan bilangan yang terdiri dari angka 0 dan 1 atau off dan on (bilangan biner). Semua sistem komputer menggunakan sistem digital sebagai basis datanya. Dapat disebut juga dengan istilah Bit (Binary Digit).

\section{METODE}

Dalam perancangan ini diperlukan sebuah penelitian untuk mengetahui lebih lanjut sejarah tentang Karaeng Pattingalloang beserta cara-cara menceritakannya kembali dalam bentuk perancangan yang baru. Perlu dilakukan sebuah analisis objek yang bersangkutan dan analisis terhadap media yang dipakai.

Teknik pengumpulan data dilakukan dengan kajian literatur, observasi lapangan dan wawancara narasumber. Narasumber terdiri atas sejarawan, akademisi dan juga budayawan. Hasil pengumpulan data kemudian dianalisis untuk dijadikan materi konsep perancangan.

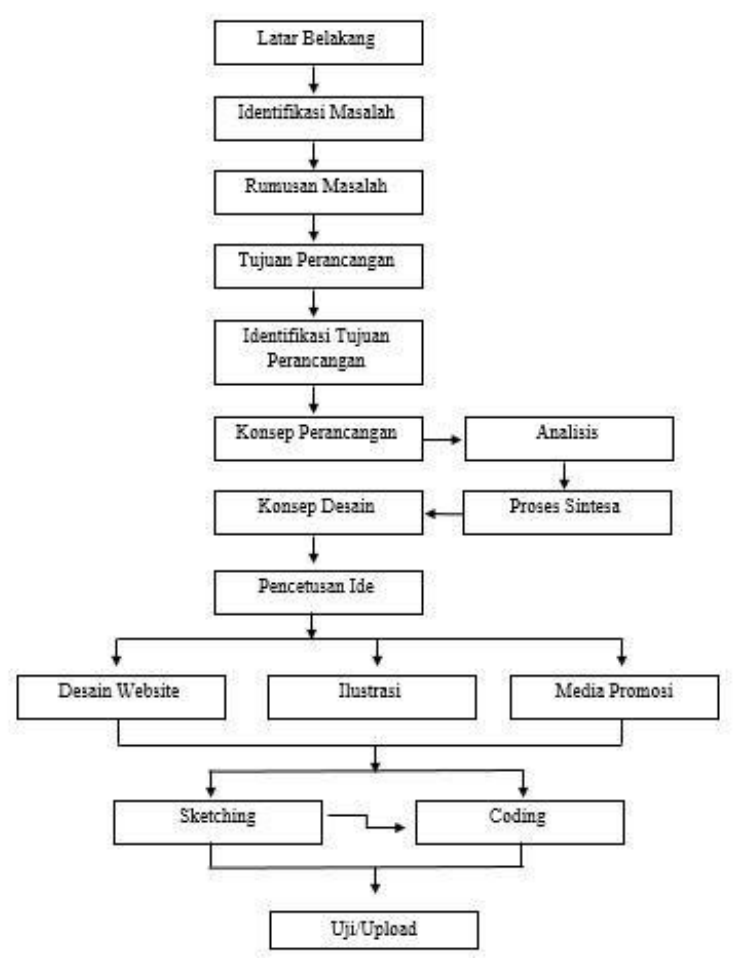

Gambar 1. Bagan Kerangka Berpikir. 


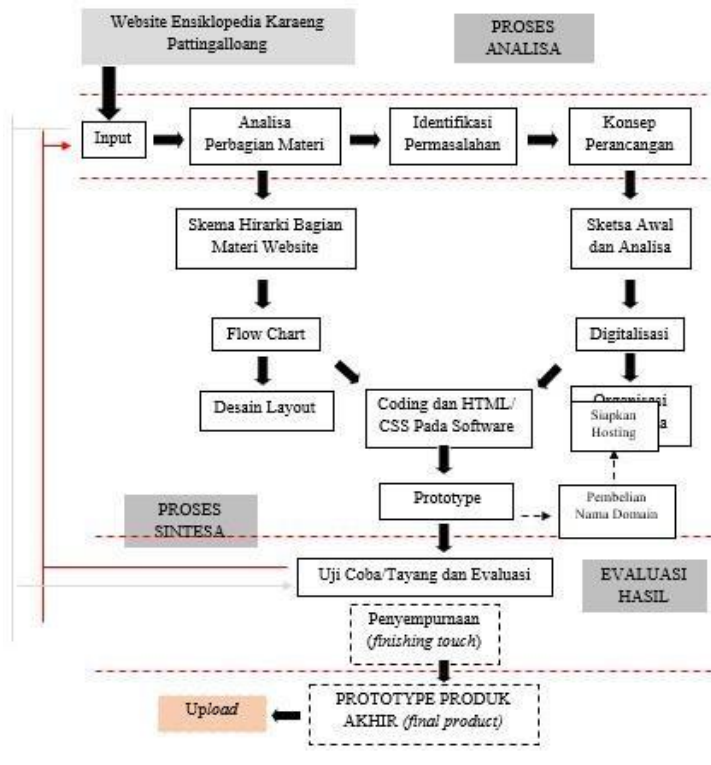

Gambar 2. Bagan Skema Perancangan.

\section{HASIL DAN PEMBAHASAN}

Karaeng pattingalloang lahir pada tahun 1600 bernama lengkap I Mangadacinna Daeng Sitaba Sultan Mahmud, Putra Raja Tallo I Malingkaang Daeng Nyonri Karaeng Matoaya. Ia pernah menjabat sebagai pelaksana Raja Tallo, karena I Mappaijo Daeng Manyuru yang diangkat sebagai Raja Tallo baru berusia 1 tahun.

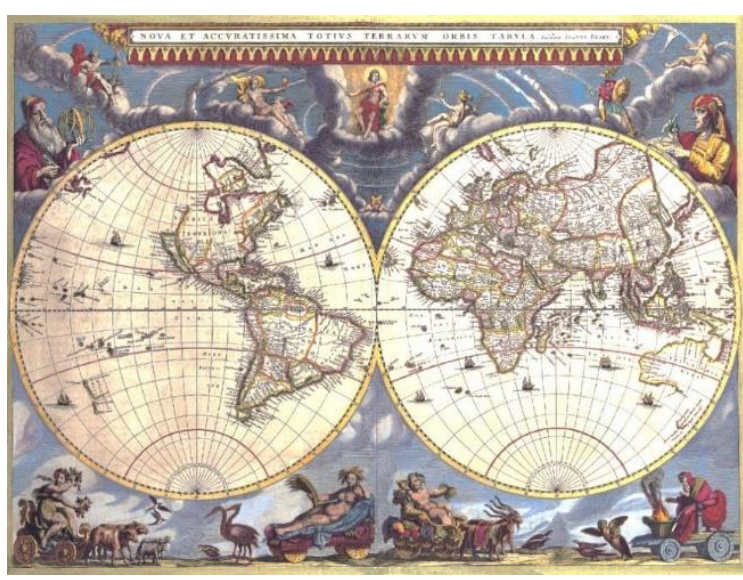

Gambar 3. Peta buatan Maior Joan Blaeu yang

Menggambarkan Sosok dari Karaeng

Pattingalloang. (Sumber:

http://cartographicperspectives.org)

\subsection{Konsep Komunikasi}

Berangkat dari tujuan perancangan ini yang sudah dikemukakan pada bab-bab sebelumnya yaitu untuk memberikan informasi kepada khalayak tentang sejarah Karaeng Pattingalloang melalui ensiklopedia digital dalam media berbentuk website, maka perancangan ini disusun berdasarkan materi sebagai berikut:

\subsubsection{Halaman Utama}

Halaman ini adalah halaman pertama yang tampil setelah seseorang memasukkan alamat situs web. Pada halaman ini berisi pengantar mengenai sejarah Karaeng Pattingalloang dan tautan-tautan menuju halaman lainnya. Sejarah Karaeng Pattingalloang pada halaman ini tidak dibahas secara terperinci melainkan hanya bersifat sebagai pengantar yang membimbing pengguna menuju halaman berikutnya.

\subsubsection{Halaman Sejarah}

Berisi tautan yang membahas secara rinci tentang Karaeng Pattingalloang yang disusun sesuai dengan urutan kejadian yang dimulai dengan sejarah berdirinya kerajaan kembar Gowa-Tallo hingga terpilihnya Karaeng Pattingalloang sebagai mangkubumi dari kerajaaan Gowa.

\subsubsection{Halaman Pesan}

Halaman ini berisi kumpulan tulisan dari Karaeng Pattingalloang yang mengandung pesan-pesan moral yang dimana diperkirakan ia pernah tulis semasa menjabat sebagai mangkubumi (tubicarayya) kerajan Gowa.

\subsubsection{Halaman Galeri}

Halaman ini berisi kumpulan foto yang berkaitan dengan Karaeng Pattingalloang ataupun peninggalan-peninggalan Kerajaan Gowa-Tallo yang masih tersisa sampai saat ini. Pada halaman ini foto-foto tersebut didampingi dengan text yang bersifat sebagai penjelasan untuk menguraikan informasi tiaptiap fotonya.

\subsubsection{Peta}

Pada bagian ini terdapat sebuah fitur yang berbentuk peta digital yang memberi informasi kepada pengunjung website mengenai lokasi-lokasi wisata yang berkaitan dengan objek perancangan. 


\subsection{Konsep Desain}

Karya yang dibuat adalah ensiklopedia digital Karaeng Pattingalloang dengan menggunakan website sebagai media utamanya. Pada perancangan ini website yang akan dibuat adalah seperti website pada umumnya namun dari segi tampilan penulis akan menambahkan ilustrasi sebagai pelengkap estetik pada tampilan website. Ilustrasi yang digunakan merupakan ilustrasi bergaya art nouveau dengan menggunakan warna-warna gelap dan kusam seperti cokelat tua dan turunannya serta warna-warna seperti pada gulungan kertas-kertas kuno untuk menimbulkan kesan masa lalu. Sedangkan gaya desain yang dipakai oleh penulis adalah menggunakan gaya scientist classic yang disesuaikan dengan gaya desain populer saat ini sehingga diharapkan kombinasi dari kedua gaya tersebut dapat menghasilkan tampilan website yang bernuansa sejarah tapi tetap terlihat modern.

\subsection{Konsep Visual}

\subsubsection{Tipografi}

Tipografi dalam perancangan ini terbagi dalam beberapa bagian, untuk penggunaan teks panjang (body text) akan lebih memperioritaskan legibilitas (keterlihatan) dan readibilitas (keterbacaan) huruf. Dalam layar, teks dengan font berjenis sans serif memiliki tingkat keterbacaan yang baik dibanding teks dengan font berjenis serif. Maka pada perancangan ini font yang digunakan penulis untuk teks panjang adalah font Roboto dan Helvetica sebagai alternatif font.

\section{Roboto Roboto Roboto ABCDEFGHIJKLMNOPQRSTUVWXYZ abcdefghijklmnopqrstuvwxyz 1234567890 \\ Helvetica Helvetica Helvetica ABCDEFGHIJKLMNOPQRSTUVWXYZ abcdefghijklmnopqrstuvwxyz

$$
1234567890
$$

Font Arial dan Helvetica untuk teks panjang (Body Text) Untuk penggunaan teks pada tiap-tiap tautan website dan sub-headline pada teks panjang maka font berjenis serif akan dipilih untuk memunculkan kesan klasik pada tampilan website namun tetap tidak melupakan sisi legibilitas dan readibilitas nya, maka font Georgia dipilih sebagai font utama.

\section{Georgia Georgia Georgia ABCDEFGHIJKLMNOPQRSTUVW}

$\mathrm{XYZ}$

abcdefghijklmnopqrstuvwxyz 1234567890

Font Georgia untuk teks pada tautan dan sub headline

\subsubsection{Logo}

Berdasarkan analisis data dan brainstorming yang telah dilakukan maka didapatkan beberapa kata kunci berupa rumah adat tradisional Makassar dan juga gulungan kertas tua yang selanjutnya dilakukan bentuk pengembangan visual logo melalui proses sketsa.

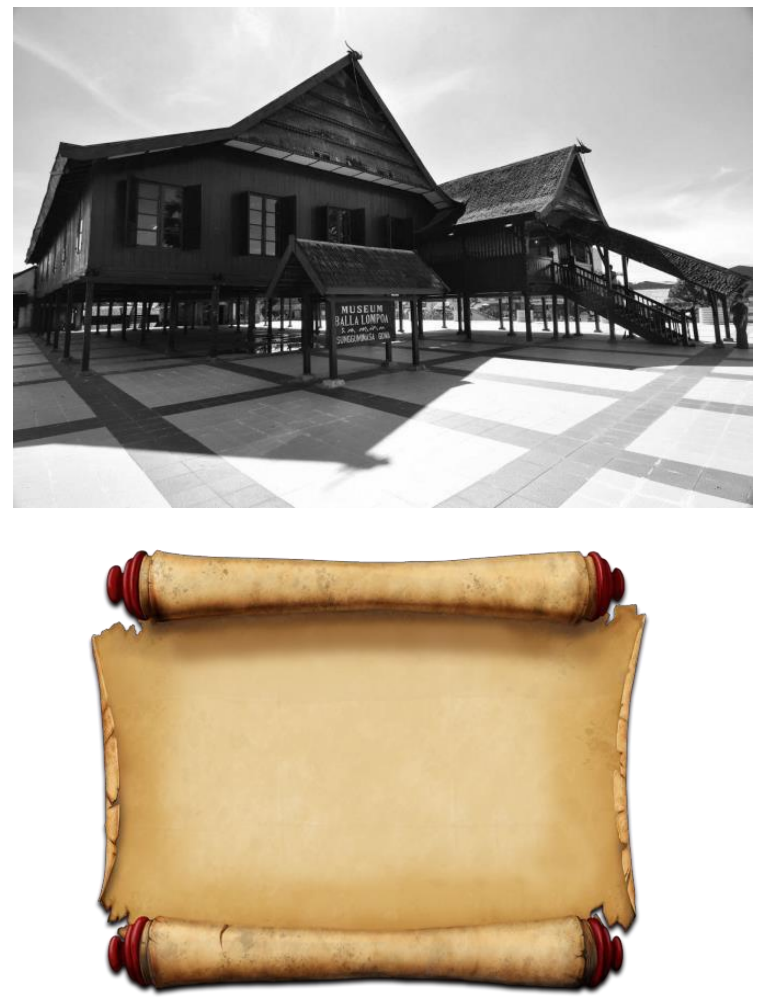

\section{Gambar 4. Rumah Adat Suku Makassar dan Gulungan Kertas Tua.}

Sketsa logo website dilakukan untuk menemukan bentuk- bentuk ideal yang dapat 
mewakili dari sosok Karaeng Pattingalloang. Bentuk-bentuk sketsa digali berdasarkan kata kunci yang diperoleh dari hasil curah gagasan (brainstorming) yang dilakukan sebelumnya. Adapun hasil dari beberapa sketsa yang telah dilakukan adalah sebagai berikut:

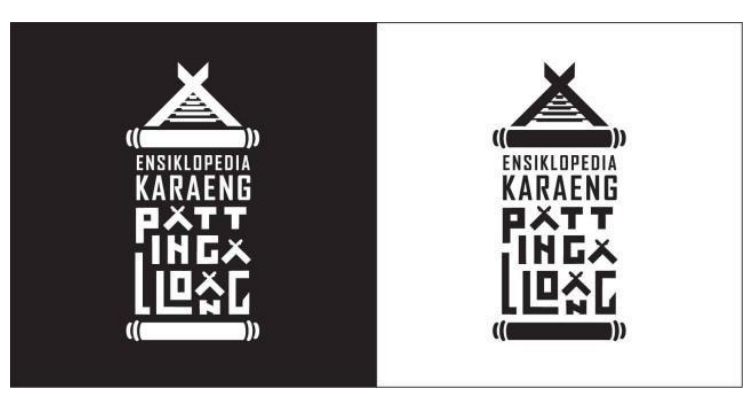

Gambar 5. Negatif-Positif Logo.

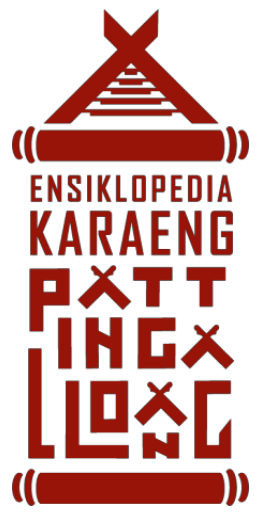

Gambar 6. Final Logo

Logo Website Ensiklopedia Karaeng Pattingalloang ini dibuat sebagai identitas yang membedakannya dengan website lain. Logo ini memakai bentuk ciri rumah adat Makassar yang memiliki atap yang unik segitiga menjulang ke atas. Selain itu lima tingkatan pada atap rumah adat Makassar memiliki makna kebangsawanan yang dapat menggambarkan sosok Karaeng. Bentuk gulungan kertas pada logo bermakna kecerdasan dan sifat intelektual dari Karaeng Pattingalloang.

\subsubsection{Layout}

Setelah melakukan proses sketsa yang dilakukan secara manual dengan menggunakan pensil, maka tahap selanjutnya adalah penulis melakukan proses digitalisasi. Proses digitalisasi ini dibantu dengan beberapa piranti grafis. Adapun hasil digitalisasi yang telah dilakukan adalah sebagai berikut:

Layout atau tata letak pada website ensiklopedia Karaeng Pattingalloang akan dirancang sefleksibel mungkin dengan tetap mempertimbangkan unsur-unsur visual yang ada di dalamnya agar tampilan karakter website tetap terjaga. Pada perancangan ini terdiri dari lima halaman utama yang masingmasing halamannya didominasi oleh text dan ilustrasi sebagai pendukung agar pesan yang ingin dikomunikasikan kepada audiens dapat tersampaikan dengan baik.

Layout atau desain tata letak pada website diambil dari bentuk-bentuk yang dianggap dapat mewakili pesan yang ini disampaikan pada perancangan website. Bentuk dasar layout website digali dari bentuk-bentuk geometris yang dapat kita jumpai dari beberapa peninggalanpeninggalan Kerajaan Gowa-Tallo ataupun objek-objek yang berkaitan. Adapun beberapa objek yang dianggap dapat mewakili pesan yang dimaksud adalah sebagai berikut:

\subsubsection{Ilustrasi}

Pembuatan ilustrasi Karaeng Pattingalloang diambil dari berbagai referensi, baik dari tokoh sejarawan langsung ataupun dari artikel-artikel yang beredar di internet. Berdasarkan hasil wawancara, peneliti dengan sejarawan tidak ditemukan gambaran pasti tentang wujud rupa asli Karaeng Pattingalloang. Semua refernsi murni hasil dari penggambaran lewat sudut pandang sendiri-sendiri. Pada perancangan ini, tidak menitikberatkan kemiripan ilustrasi dengan objek yang diteliti, akan tetapi lebih kepada kesesuain gaya visual dengan target yang dituju.

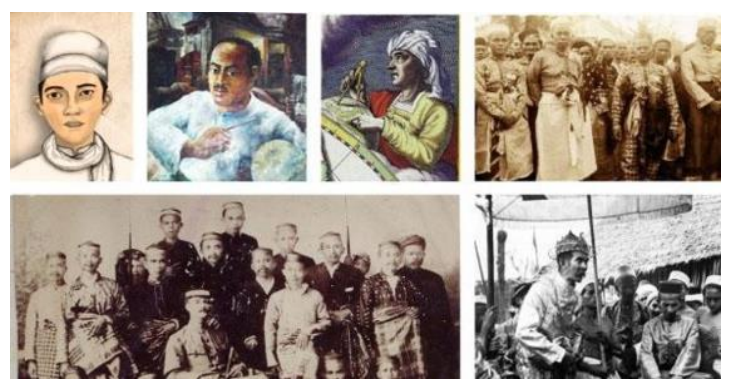

Gambar 7. Sumber inspirasi dan Referensi Ilustrasi. (Sumber: Pribadi dan Internet) 


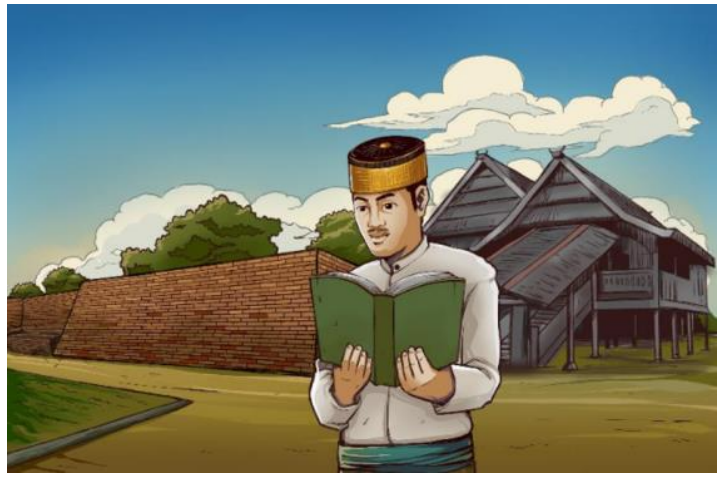

Gambar 8. Hasil Akhir Ilustrasi. Pattingalloang.

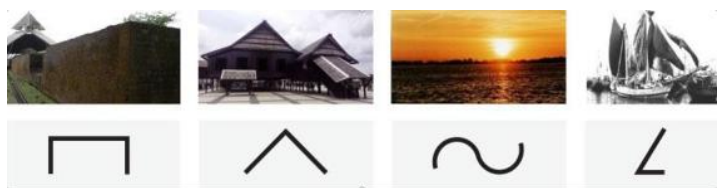

Gambar 9. Sumber Inspirasi Desain Layout.

Setelah memilih alternatif desain yang dipakai, maka tahap selanjutnya adalah melakukan proses digitalisasi desain layout website. Pada proses ini hasil sketsa yang terpilih kemudian dipindahkan untuk digitalkan melalui bantuan piranti grafis.

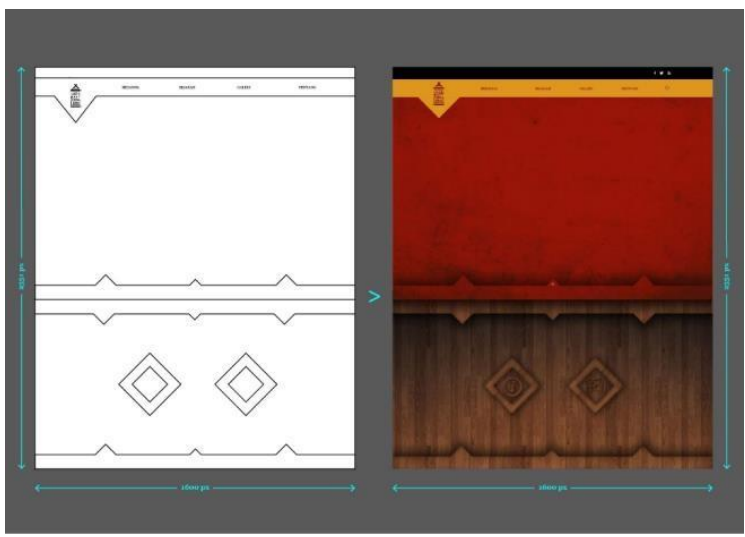

Gambar 10. Halaman Beranda Website.

Pada halaman beranda website ensiklopedia digital Karaeng Pattingalloang berisi tampilan ilustrasi yang mengambarkan Karaeng Pattingalloag beserta latar rumah adat Makassar dan benteng Somba Opu. Penempatan ilustrasi pada halaman utama beranda bertujuan untuk membangun persepsi awal kepada pengunjung website agar kesan sejarah yang ingin disampaikan dapat dimengerti langsung oleh para pengunjung. Selain itu juga pada halaman beranda terdapat logo website yang ditempatkan pada bagian header atas beserta tombol- tombol navigasi utama yang telah dijelaskan pada pembahasan sebelumnya.

\section{SIMPULAN DAN SARAN}

Dari hasil perancangan Website Ensiklopedia Digital Karaeng Pattingalloang, maka diperoleh kesimpulan sebagai berikut:

Dalam perancangan sebuah website ensiklopedia digital banyak hal yang perlu diperhatikan dalam hal kesesuaian tampilan dengan konsep perancangan, seperti tata letak gambar, elemen-elemen grafis, huruf danl lainnya karena pada dasarnya bahasa pemograman pada website tidak sesederhana yang dikira.

Karaeng Pattingalloang sebagai Mangkubumi atau Perdana Menteri dari Kerajaan Gowa-Tallo pada masa pemerintahan Raja Gowa ke XV Sultan Malikusaid, memang layak untuk diangkat sebagai tauladan bagi masyarakat Sulawesi Selatan pada khususnya atas pencapainpencapainnya di masa lampau.

Pemilihan media utama yang dihasilkan berupa website sangat relevan digunakan di era digital seperti sekarang ini dimana masyarakat pada umumnya dapat mengakses internet dengan mudah dimanapun dan kapanpun baik melalui gawai atau perangkat pintar dan komputer yang mereka punya.

\section{REFERENSI}

Zainudin Tika, M. Ridwan Syam. 2011. KaraengPattingalloang Raja Tallo, Makassar: Pustaka Refleksi.

Drs. H. Hannabi Rizal, M. Pd, Zainuddin Tika, SH, Drs, M. Ridwan Syam. 2004. Profil Raja Dan Pejuang Sulawesi Selatan, Sungguminasa: Percetakan Buana.

Tinarbuko, Sumbo. 2015. Desain Komunikasi Visual Penanda Zaman Masyarakat Global, Yogyakarta: CAPS (Center ForAcademic Publishing Service).

Surianto Rustan. 2011. Font Dan Tipografi, Jakarta: Gramedia Pustaka Utama. 


\section{imajina}

Surianto Rustan. 2009. Mendesain Logo, Jakarta: Gramedia Pustaka Utama.

Bima Nurin Aulan, Irfansyah, Alvanov Z. Mansoor.

2013. Perancangan Ensiklopedia Digital Interaktif Tokoh Wayang Kulit Cirebon Pada Mobile Device, Jurnal Komunikasi Visual \& Multimedia. Vol. V. (2): 23-40.

Tegar Andito. 2013. Perancangan Website Ensiklopedia Digital Museum Kereta Api Ambarawa, Tesis tidak diterbitkan. Yogyakarta: Institut Seni Indonesia Yogyakarta. 